\title{
UMA ANÁLISE SOBRE A INSERÇÃO DE ALUNOS COM NECESSIDADES ESPECIAIS EM UMA ESCOLA PÚBLICA MUNICIPAL DE FORTALEZA-CE
}

\author{
Francisca Edileuza Vitor de Sousa ${ }^{\mathrm{I}}$ \\ Marcel Pereira Pordeus ${ }^{2}$
}

RESUMO: Este artigo é um recorte da minha dissertação de mestrado em Ciências da Educação, e tem por finalidade ressaltar a importância da educação para todos, tendo como foco de pesquisa do tema uma análise crítico-reflexiva sobre a inserção de alunos com necessidades educacionais especiais no Ensino Fundamental. No primeiro momento desse trabalho foi feita uma leitura vertical sobre as leis e dispositivos legais que delinearam todo o processo de Educação Especial. Em seguida, uma análise crítica diagnóstica sobre o espaço de ação, ou seja, a unidade escolar que motivou essa pesquisa, com base na sua prática de educação inclusiva para alunos com necessidades educacionais especiais, seus entraves e desafios, e fundamentando alguns pontos críticos com literaturas de teóricos que abordam e problematizam a forma de inserção de alunos com necessidades educacionais especiais, atualmente, nas escolas públicas de ensino regular. No final, pontuações foram realizadas e ações com o empenho de todos que compõem cada unidade escolar e com o compromisso dos governantes pôde-se mudar o conceito presente, que é na maioria das escolas só receber o aluno garantindo sua matrícula e ficando em segundo plano o desenvolvimento das habilidades e formação para a inserção no mercado de trabalho. Conclui-se que as escolas inclusivas devem reconhecer e responder às diversas necessidades de seus alunos, assegurando uma educação de qualidade, com professores capacitados, respeitando o ritmo de aprendizagem e as habilidades de cada aluno. Pois, com a Declaração de Salamanca efetivou-se o compromisso de garantia dos direitos educacionais, afirmando que as escolas regulares inclusivas devem acolher todas as crianças, independentes de suas condições físicas, intelectuais, sociais, emocionais ou linguísticas.

Palavras-chave: Inclusão. Alunos com necessidades educacionais especiais. Ensino Fundamental.

\section{INTRODUÇÃO}

Etimologicamente, a palavra inclusão vem do latim, do verbo includere e significa "colocar algo ou alguém dentro de outro espaço, entrar num espaço até então

\footnotetext{
${ }^{I}$ Mestra em Ciências da Educação pela Universidad Interamericana. E-mail: edleuzavitor@gmail.com. 2 Mestrando no programa de pós-graduação em Planejamento e Políticas Públicas da Universidade Estadual do Ceará (UECE). Graduando em Relações Públicas pela Universidade Federal de Santa Maria (UFSM). Graduado em Letras pela Universidade Federal do Ceará (UFC). E-mail: marcel.pordeus@aluno.uece.br.
} 
fechado." É a junção do prefixo in (dentro) com o verbo (cludere), que significa “encerrar, fechar, clausurar”. Entendendo-se, por Educação Inclusiva, como um processo de inclusão de portadores de necessidades especiais ou de distúrbios de aprendizagem nos diversos graus de ensino. Nas últimas décadas em nosso país, a inclusão de alunos com necessidades educacionais especiais, no sistema regular de ensino, tem sido, sem dúvida, a questão mais discutida. A Educação Inclusiva atualmente tornou-se proposta das Políticas Públicas Educacionais, tanto em nível federal, quanto estadual e municipal, amparada e fomentada pela legislação em vigor.

Por volta do século XIX, mais precisamente na segunda metade, surgiram no Brasil algumas instituições que atendiam pessoas com deficiências, porém, não fica claro se era um atendimento educacional ou outros tipos de assistência, e não tinha uma demanda em nível nacional. A Educação Inclusiva surgiu para atender e garantir os direitos básicos inerentes a todos, tema esse, recorrente em muitas discussões que envolvem a educação e a inclusão de todos, nas últimas décadas, de acordo com a Declaração Universal dos Direitos Humanos em seu Artigo Io: “Todos os seres humanos nascem livres e iguais em dignidade e em direitos".

Muitas leis e dispositivos legais têm surgido a partir do final do século XX com objetivos claros, no âmbito da Educação Inclusiva, com garantias de acesso igual a todos, em espaços destinados a vida humana. O grande desafio, no entanto, foi romper com os paradigmas entranhados em práticas muito consolidadas. Sair de uma forma padrão e enveredar em algo novo, no diferente, com situações diversas, sem dúvida requer muito empenho de todos, não só dos governantes, mas também de toda a sociedade. $O$ processo de inclusão não é compromisso só de determinados segmentos, é um desafio daqueles que defendem direitos igualitários aos seres humanos, independentes de suas peculiaridades, pois cada indivíduo é único, singular em suas características e precisa ser respeitado (PORDEUS, 2020).

Sabe-se que a escola é um dos espaços de interação social, com grande peso no contexto de uma comunidade. É da escola a função de receber as crianças que serão inseridas no ensino regular, independentes de quaisquer necessidades educacionais especiais que alguns venham a apresentar. De acordo com a Constituição Federal de I988, em seu art. 206, que estabelece no inciso I: “[...] aigualdade de condições para o acesso e permanência na escola”. E no inciso IV: "respeito à liberdade e apreço a tolerância”. 
O espaço escolar deve permitir as interações entre os alunos com suas potencialidades, para que as manifestações de aprendizagem possam ser compartilhadas na diversidade humana, respeitando suas capacidades e limitações, procurando desenvolver qualquer ação pedagógica que lhes sejam apresentadas. A política de inclusão de alunos que apresentam necessidades educacionais especiais, na rede regular de ensino, não consiste apenas na permanência física desses alunos junto aos demais educandos, mas representa a ousadia de rever concepções e paradigmas, bem como desenvolver o potencial dessas pessoas, respeitando as diferenças e atendendo suas especificidades (PORDEUS, 2020).

Esse novo olhar da escola implica na busca de alternativas que garantam o acesso e a permanência de todas as crianças e adolescentes no seu interior. Assim, o que se almeja é a construção de uma sociedade inclusiva comprometida com as minorias, cujo grupo inclui as pessoas com necessidades educacionais especiais. $\mathrm{O}$ ambiente escolar, hoje, deve visto como espaço de todos e para todos.

Com todo amparo legal, e garantias claras, o processo de inclusão ainda tem que vencer muitos obstáculos, percorrer um longo caminho, das leis até a prática, no contexto da escola; lugar em que deve acontecer a inclusão de forma legítima, reconhecendo e respeitando os direitos daqueles que apresentam necessidades educacionais especiais. Portanto, é necessário que a sociedade crie condições para lidar/incluir as pessoas com necessidades educacionais especiais no processo educativo, contribuindo para superar o modelo de educação que, segundo André (200o), ainda é preconceituoso ao se defrontar com as variedades comportamentais, raciais e de aprendizagem. A autora afirma que as formas de vencer esses preconceitos não são discutidas durante a formação do professor.

Enfim, tratar o tema inclusão, é de total relevância para a sociedade, posto não ser justo que em pleno século XXI, ainda nos deparemos com situações em que indivíduos sejam marginalizados por apresentarem características diferentes, ou por fugirem a paradigmas preestabelecidos.

\section{Um Breve Histórico Sobre a Inclusão}

A política de Educação Inclusiva tem surgido com alguma relevância em um período não muito distante. $\mathrm{O}$ conceito de cidadania ganha um desenho mais definido nas 
últimas décadas, levando em conta os princípios básicos inerentes a todos os seres humanos. Contudo, nem sempre foi assim, registros mostram os dois primeiros períodos com ações pontuais sobre a inclusão na educação, antes denominada como Educação Especial, porque nas instituições o atendimento era direcionado a pessoas com deficiências. A primeira fase compreende o período de 1854 a 1956. No decorrer desse século, surgiram algumas instituições, no atendimento a pessoas com necessidades educacionais especiais, porém, atendiam a deficiências específicas "com iniciativas oficiais e particulares isoladas”, concentrando-se mais, nas regiões sudeste, ou seja, no eixo Rio e São Paulo.

Com bases em literaturas da educação e documentos técnicos, não fica evidente que o atendimento a pessoas com deficiências fosse de fato educacional, "pois numa análise criteriosa pode-se constatar tratar-se de outros propósitos”. Procurando, na história da educação, informações significativas a respeito do atendimento educacional de pessoas com deficiência, pode-se verificar que, até o século XVIII, as noções sobre deficiência estavam basicamente ligadas ao misticismo e ocultismo, não existindo base científica para que fosse possível desenvolver noções realísticas. $O$ conceito de diferenças individuais não era compreendido ou avaliado. "As noções de democracia e igualdade eram ainda meras centelhas na imaginação de alguns indivíduos criadores" (MAZZOTTA, 2oir, p. 16).

O primeiro registro, no Brasil, de instituição para atendimento adeficientes, data de 12 de setembro de 1854 , que através do Decreto Imperial n. I428, D. Pedro II fundou, na cidade do Rio de Janeiro, o Imperial Instituto dos Meninos Cegos, graças a um brasileiro deficiente visual, José Álvares de Azevedo, após ter estudado em Paris, e de volta ao Brasil teve uma experiência exitosa na educação de Adélia Sigaud, filha do Dr. José F. Xavier Sigaud, então médico da família imperial, e pela influência de Couto Ferraz, ministro do Império. E para assumir a direção do instituto foi nomeado o Dr. Xavier Sigaud, "[...] cujo busto em mármore se encontra no salão nobre daquela casa de ensino" (MAZZOTTA, 20II, p. 28).

Após 36 anos, através do Decreto n. 408, seu nome foi alterado para Instituto Nacional dos Cegos, e em 24 de janeiro de I89i, pelo Decreto n. 1320, a escola passou a denominar-se Instituto Benjamin Constant (IBC), sendo feita uma homenagem a um 
“[...] ilustre e atuante ex-professor de Matemática e ex-diretor da instituição, Benjamin Constant Botelho de Magalhães (MAZZOTTA, 2011, p. 29).

Nota-se que foi um caso particular e atendia a uma determinada deficiência, em uma cidade do Brasil e com o apoio e a simpatia do Imperador. Todavia, dava-se início a uma vertente que viria desencadear outras ações com objetivos no atendimento de pessoas com outras deficiências. Em 1857, ainda no Império de D. Pedro II, foi criado na cidade do Rio de Janeiro, o Imperial Instituto dos Surdos-Mudos, com indicação de Ernesto Hüet e seu irmão, cidadão francês que chegou no Rio de Janeiro no final de 1855 e com as graças e anuência do Imperador que lhe concedeu a importante tarefa de fundar a escola de surdos-mudos no Brasil; começando a lecionar para dois alunos, e no ano seguinte, mais precisamente, em outubro de 1856 passou a ocupar todo prédio da escola, onde nascia ali o Imperial Instituto dos Surdos-Mudos. Cem anos depois de sua fundação passaria a denominar-se Instituto Nacional de Educação de Surdos, (INES), sob aLei n. 3.198, em 6 de junho de 1957.

É importante frisar que essa escola tinha seu objetivo voltado para "educação literária e o ensino profissionalizante" direcionados a meninos surdos-mudos, na faixa etária entre 7 a 14 anos. E mais tarde, os dois institutos passam a desenvolver, através de suas oficinas, o conhecimento prático de ofícios, estando assim definidos: tipografia e encadernação para meninos cegos e tricô para as meninas; sapataria, encadernação, pautação e douração para os meninos surdos, dando início a uma oportunidade desses deficientes, através de suas habilidades, desenvolverem uma atividade remunerada e poder fazer jus a um dos direitosinerentes ao cidadão, que é o exercício do trabalho. No entanto, em termos nacionais, o número de contemplados com esses atendimentos ainda era ínfimo: de uma população de 15.848 cegos e de 1 I. 595 surdos, eram atendidos 35 cegos e I7 surdos, confirmando que esses números são insignificantes mediante aos números de deficientes apresentados no ano de 1872.

Por determinação do Imperador, em I883, no Io Congresso de Instrução Pública, tendo a possibilidade de se discutir a educação dos portadores de deficiência, surge a primeira oportunidade de se colocar em pauta a "sugestão de currículo e formação de professores para cegos e surdos”. Registra-se ainda, no Segundo Império, o Hospital de Salvador, na Bahia, atualmente, Hospital Juliano Moreira, com atendimento direcionado a deficientes mentais, porém, não fica clarose era um atendimento educacional ou outros 
tipos de atendimento (assistência médica ou médico-pedagógico).

De acordo com Mazzotta (20II), até meados do século XX o Brasil contabilizava quarenta estabelecimentos de ensino regular público, sendo um federal e os demais estaduais, com atendimento escolar especial, a deficientes mentais e ainda, catorze estabelecimentos de ensino regular: um federal, nove estaduais e quatro particulares; com atendimento a alunos com outras deficiências. Somava-se também, mais três instituições especializadas, (uma estadual e duas particulares) no atendimento de deficientes mentais e outras oito (três estaduais e cinco particulares) direcionadas à educação de outros deficientes.

Em 1961, estava em vigor a Lei de Diretrizes e Base da Educação Nacional (LDBEN) - Lei no 4.024, que assegurava o direito à educação em escolas de ensino regular para as crianças com necessidades especiais ou superdotadas. Entretanto, na década de 1970 houve um retrocesso na inclusão educativa com a aprovação da Lei $\mathrm{n}^{\circ}$ 5.692/7I, que determinava tratamento especializado para os alunos com deficiência, reforçando assim a segregação desses alunos em salas especiais. Na mesma época foi criado o Centro Nacional de Educação Especial (CENESP), que era responsável pela educação especial no país, promovendo o movimento da integração escolar dos sujeitos com limitações físicas ou mentais.

A Lei $n^{\circ} 7.853 / 89$ foi regulamentada por meio do decreto $n^{\circ} 3.298$ em 1999, que organizava a Política Nacional para a Integração da Pessoa Portadora de Deficiência, determinado o conceito de deficiência, definindo quem eram esses indivíduos e, a partir disso, como os mesmos seriam assegurados. Essa lei afirmava que deficiente é todo aquele que tem uma perda ou uma anormalidade de uma estrutura ou função psicológica, fisiológica ou anatômica que provoque limitações para desenvolver algum tipo atividade, que esteja dentro do padrão considerado normal para os demais, e afirma ainda que deficiência permanente é aquela que ocorreu em um determinado tempo sem recuperação, mesmo com novos tratamentos.

Segundo o decreto supracitado em seu artigo $4^{\underline{o}}$, a pessoa tem uma deficiência física quando possui uma alteração completa ou parcial de uma ou mais partes do corpo, causando assim prejuízo para o desenvolvimento da função física e apresentando-se como: paraplegia, paraparesia, monoplegia, tetraplegia, triplegia, triparesia, hemiplegia, ostomia, amputação ou ausência de membro, paralisia cerebral, 
Revista Ibero- Americana de Humanidades, Ciências e Educação- REASE

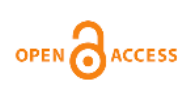

nanismo, deformidade congênita dos membros ou adquirida, ressalvadas as deformidades estéticas e as que não alteram o desenvolvimento de funções.

De acordo com o mesmo artigo, do referido decreto, tem deficiência auditiva aquele que apresenta uma perda bilateral, parcial ou total, de quarenta e um decibéis (dB) ou pela medida do audiograma nas frequências de $500 \mathrm{HZ}, 1000 \mathrm{HZ}, 2000 \mathrm{~Hz}$ e $3000 \mathrm{~Hz}$. Enquanto que o deficiente visual é aquele que tem uma acuidade visual no melhor olho de igual ou menor a 0,05 , isso com uma boa correção óptica; já a baixa visão, a acuidade visual no melhor olho fica entre 0,3 e 0,05, com a melhor correção óptica; e a somatória das medidas do campo visual nos dois olhos for igual ou menor que $60^{\circ}$.

E por último, o mesmo artigo com relação à deficiência mental, refere-se que o funcionamento intelectual significativo do sujeito é inferior à média, antes de dezoito anos e com limitações em duas ou mais áreas de habilidades adaptativas, como na comunicação, cuidado pessoal, habilidades sociais, utilização dos recursos da comunidade, saúde e segurança, habilidades acadêmicas, lazer e trabalho. Por fim, o decreto em tela define deficiência múltipla como aquela que engloba duas ou mais deficiências.

O Decreto no 6.949/o9 publicou que a Convenção de Nova Iorque, conceitua pessoa com deficiência, seja de natureza física, mental, intelectual ou sensorial, como aquela que "está impedida por longo prazo de interagir com sua participação plena na sociedade em igualdade com as outras pessoas”. Já a Constituição Federal, em seu artigo $3^{\mathrm{o}}$, inciso $5^{\mathrm{o}}$, define que a União, Distrito Federal, os Estados e os Municípios têm como objetivo fundamental "promover o bem de todos, sem preconceitos de origem, raça, sexo, cor, idade e quaisquer outras formas de discriminação” (BRASIL, 2007, n/p). Outros artigos da Constituição Federal, como o 205 que assegura a frequência de todos às escolas regulares do sistema, determinando que: “A educação, direito de todos e dever do Estado e da família, será promovida e incentivada com a colaboração da sociedade, visando ao pleno desenvolvimento da pessoa, seu preparo para o exercício da cidadania e sua qualificação para o trabalho" (BRASIL, 1988, p. 56).

Já o artigo 206 garante a igualdade de condições a todos, com relação ao acesso a educação regular. Nessa perspectiva, o artigo 208, inciso $3^{\circ}$ determina queé obrigação do do Estado garantir o atendimento educacional especializado a pessoas com necessidades 
especiais, preferencialmente na rede regular de ensino (BRASIL, I988 p. 56).

O Estatuto da Criança e do Adolescente (ECA), por meio da Lei no 8.069/9o, em seu art. 55 determina que cabe aos pais ou responsáveis a obrigatoriedade de matricular seus filhos na rede regular de ensino.

\section{Situação da Educação na Capital Cearense}

De acordo com o Censo Escolar da Educação Básica (CEEB, 2017), divulgado pelo Instituto Nacional de Estudos e Pesquisas Educacionais Anísio Teixeira(Inep), a Rede Municipal de Ensino de Fortaleza registrou aumento no número de matrículas em todas as faixas de ensino. O resultado vai na direção oposta do Brasil,que reduziu o número de matrículas no Ensino Fundamental nas escolas públicas.

$\mathrm{Na}$ capital cearense, a matrícula foi ampliada na comparação com 2016, passando de 197.381 para 207.302 alunos (aumento de 5,03\%). De acordo com o Censo Escolar, a expansão de matrícula ocorreu tanto na Educação Infantil (+9,63\%) - com destaque para as vagas de creche (+10,53\%) - como no Ensino Fundamental (+4,02\%) com maior aumento entre as turmas de $6^{\circ}$ ao $9^{-0}$ ano $(+6,29 \%)$ - e, tambémna Educação de Jovens e Adultos (+2,78\%).

Ainda segundo o CEEB (2017), Fortaleza foi destaque nacional, ainda, no atendimento em Tempo Integral, com aumento de $108,9 \%$ na rede pública, um dos maiores crescimentos do País. Só no Ensino Fundamental, a expansão foi de 169,8\%, enquanto na Educação Infantil as matrículas cresceram em 17,1\%. A outra modalidadeque acompanhou a evolução foi a Educação Inclusiva, com acréscimo de 4I,4\% nas matrículas entre 2016 e 2017 .

Pode-se considerar o Censo Escolar como o principal instrumento de coleta de informações da Educação Básica e o mais importante levantamento estatístico educacional brasileiro na área. É coordenado pelo Inep, que é um órgão vinculado ao Ministério da Educação, realizado em regime de colaboração entre as secretarias estaduais e municipais de educação e com a participação de todas as escolas públicase privadas do país. Em Fortaleza, no ano de 2017, segundo o Censo Escolar/Inep (2017)tiveram, especificamente, 35. 775 estudantes matriculados no 60 ano, da rede pública e privada, na localização urbana e rural.

Um motivo importante é dirigido aos conflitos familiares, a falta de 
acompanhamento e estímulo dos pais referente aos assuntos escolares, à falta de convivência com os filhos em consequência a uma jornada de trabalho cada vezmais extensa, e a particularização dentro do próprio lar provocada pelos avanços tecnológicos etc. Cabrera y La Nasa (200o) mostram que a posição socioeconômica dos pais e suas respectivas experiências acadêmicas trarão impactos na trajetória educacional dos filhos. Pois, na maioria dos casos, quanto maior o índice de escolaridade dos pais, maior será a importância dada à vida escolar dos filhos.

Bauman (2013) afirma que jamais na história da humanidade foi tão árdua a tarefa de fazer escolhas, tendo em vista que o espectro da fluidez, do dejeto, do descarte está impelindo para a constante ameaça de ficar para trás, de ser excluído e preterido por outro. Diante da condição de provisoriedade e das incertezas, ojovem convive cotidianamente com a ameaça de ser excluído do jogo, de ser incapaz de atender as novas exigências e demandas. Essa ansiedade constante em muitos casos, leva a uma perda de perspectiva de futuro, invadindo o presente e gerando certa imobilidade diante dos fatos.

Percebe-se que a partir da Declaração Mundial de Educação para todos (1990), os direitos humanos das pessoas com deficiência passaram a ser mais respeitados, também constata-se, nessas três décadas, a constituição e o crescimento de um mercado voltado para a produção de bens e serviços destinados a atender as necessidades das pessoas com deficiência, que assim passaram à condição de consumidores ativos mais do que de produtores no mercado globalizado. No setor de serviços, passa-se a assistir a uma proliferação de especialistas no atendimento clínico, psicológico e educacional das pessoas com deficiência, que combinados à implementação de políticas públicas para a inclusão dessas pessoas na escola e na sociedade, resultaram na criação de milhares de postos de trabalho no mundo inteiro.

Dessa forma, conclui-se que a merco-inclusão ainda que tenha contribuído para a afirmação dos direitos das pessoas com deficiência, vem fomentando um mercado paradoxal, uma vez que o grande negócio da inclusão exclui todos aqueles que não podem pagar por esses produtos e serviços, ou no máximo dá a estes excluídos o papel de beneficiários de políticas públicas. Por sua vez, essas políticas públicas são terceirizadas, movimentando milhões de cifras no terceiro setor da economia, explorado por Organizações não Governamentais ONG's de toda natureza, que disputam com todas as 
armas as parcerias com o poder público, no afã de prestar serviços às pessoas com deficiência pertencentes à base da pirâmide social capitalista, enriquecendo essas organizações, que por suas limitações e interesses acabam prestando um desserviço à inclusão. Longe detransformar a escola e assim a sociedade, a política de inclusão acaba assimilada como mais uma reforma do capitalismo e como tal contribui para sua perpetuação e, portanto, para a perpetuação da exclusão.

\section{CONCLUSÃO}

Embora muitos conheçam o conceito de Inclusão, o processo pode ser muito difícil. Compreender as políticas públicas e as leis que perpassam essa trajetória, abrange esforço e habilidades, pois transita pela modernização a reestruturação de muitos requisitos presentes na maioria das escolas.

Obstáculos são enfrentados cotidianamente para mudar as situações excludentes de ensino e aprendizagem. É desafiador inserir um novo projeto, como o da inclusão em um modelo antigo do conceito escolar, necessitando que o modeloeducacional vigente seja reformulado. Constata-se que as escolas que reconhecem e valorizam as diferenças procuram desenvolver projetos educacionais inclusivos, procurando atender às especificidades dos educandos com atraso escolar, devido a não capacidade de acompanhar os colegas da turma.

Tomando como base a realidade da escola em análise, não é muito difícil perceber que a inclusão de alunos com necessidades especiais, não se efetiva, é mais uma maneira de atender um imperativo de governo. Sabe-se que as escolas públicas atravessam situações bem complicadas, em todos os setores; ora, se a educação no Brasil está aquém do desejado, o que levaria a crer que com o processo de Educação Inclusiva seria diferente?

Percebe-se também, que nem todos os educadores possuem o devido preparo para a educação inclusiva, e isso pode levar a resistências de alguns às inovações da educação, como a inclusão, ao considerarem que a proposta de uma educação para todos é válida, entretanto, impossível de ser concretizada, levando em conta a quantidade de alunos e as circunstâncias em que se trabalha nas escolas regulares do ensino público. Demonstra-se, mais do que nunca, que os professores devem capacitar-se, acreditar e, 
principalmente, aceitar a inclusão, tornando assim a sua sala de aula um ambiente propício à construção do conhecimento, tanto do aluno com necessidades especiais, quanto dos demais.

Entende-se que as políticas de inclusão enfrentam um grande desafio, entretanto, com grande oportunidade para a construção de um outro mundo, mais humano e mais justo, no qual todos possam viver em harmonia e de modo sustentável, pois a inclusão não é só uma política, mas um caminho que se trilha ao construir. Porém, na unidade escolar pode-se sim, fazer a diferença, enfrentar os desafios, driblar os obstáculos do dia a dia. Mas, para que isso aconteça é preciso contar com uma equipe que esteja em sintonia, a escola torne-se um espaço humanizado e as ações devem ser planejadas com a participação de todos, desde a elaboração do PPP, até o fazer em sala de aula.

Esse planejamento deve ocorrer no início de cada ano com todos os segmentos da escola, e tudo deve ser previsto, discutido e definido em comum acordo. Os alunos com necessidades educacionais especiais são em minoria em relação aos outros considerados “normais”, mas não deixam de ser importantes, continuam sendo seres com direitos, mas, com esse formato de Inclusão, passam a ser meros objetos ou no pior das hipóteses, indivíduos invisíveis. A escola precisa sair de sua zona de conforto, deixar de ser um local de pelejas e embates, em que cada um cuida de si, e tornar-se uma unidade.

Enfim, observa-se que faz-se necessário que os gestores, professores e os demais funcionários sejam capacitados cada um dentro de sua especificidade para melhor atender principalmente aos alunos com necessidades educacionais especiais, envolvendo todo ambiente escolar, com um PPP que contemple a Educação Inclusiva e com estrutura física adequada.

\section{REFERÊNCIAS}

ANDRÉ, Marli. É hora de aceitar e valorizar as diferenças. In: Revista Nova

Escola. São Paulo, ed. 138, dezembro, p. 42, 2000.

BAUMAN, Z. Sobre juventude e educação: conversas com Ricardo Mazzeo. Rio de Janeiro: Zahar, 2013.

BRASIL. Constituição (1988). Constituição da República Federativa do Brasil. Brasília, DF: Senado Federal, 1988. 
BRASIL. Lei 5.692, de 1971. Fixa diretrizes e bases para o ensino de primeiro esegundo graus, e da outras providencias. Diário Oficial da República federativa do Brasil, Brasília, DF,12 de ago. 197I.

BRASIL. Política Nacional de Educação Especial. Série Livro. Brasília, DF: MEC/SEESP, 1994 .

BRASIL. Lei n. 4.024/196r. Fixa as Diretrizes e Bases da Educação Nacional. Brasília, ig6r.

BRASIL. Lei n. 5.692/1971. Fixa Diretrizes e Bases para o ensino de $1^{\circ}$ e $2^{\circ}$ graus, e dá outras providências. Brasília, 197ı.

BRASIL. Lei n. 9.394/1996. Estabelece as diretrizes e bases da educação nacional. Brasília, 1996.

BRASIL. Ministério da Educação. Secretaria de Educação Especial. Política Nacional de Educação Especial na Perspectiva da Educação Inclusiva. Brasília: MEC/SEESP, 2007.

BRASIL. Ministério da Educação. Instituto Nacional de Estudos e Pesquisas Educacionais Anísio Teixeira (INEP). Diretoria de Estatísticas Educacionais (DEEd). Censo escolar da educação básica 2017. Brasília, DF: MEC/INEP, 2018.

BRASIL. Lei no. 8.069, de 13 de Julho de 1990. Estatuto da Criança e do

Adolescente. 13. ed. São Paulo: Atlas, 2006.

CABRERA, A.; LA NASA, S.M. On the path to the college: three critical tasks facing american'sdisavanteged. In: Research in Higher Educacion, v. 42, n. 2,200I.

PORDEUS, M. P.. Políticas Públicas Educacionais para inclusão e movimento das pessoas com deficiência (PCD). 2020. XVII CIDH Congresso Internacional de Direitos Humanos, 2020. (Apresentação de Trabalho/Congresso).

MAZZOTTA, M. J. da S. Política Nacional de Educação Especial. CadernosCEDES 23, Educação Especial, p. 5-16, 1994.

MAZZOTTA. Educação especial no Brasil: história e políticas públicas. 6. ed. São Paulo: Cortez, 201 . 